\title{
Precipitation of Nano-Sized Carbides in a Ti-Mo Bearing Steel at a Low Transformation Temperature
}

\author{
Chih Yuan Chen ${ }^{1,3}$, Shih Fan Chen ${ }^{2,}$, Jer Ren Yang ${ }^{1}$, and Chien Chon Chen ${ }^{3, *}$ \\ ${ }^{1}$ Department of Materials Science and Engineering, National Taiwan University, Taipei 10617, $\operatorname{Taiwan}^{2}$ In- \\ stitute of Materials Science and Engineering, National Taipei University of Technology, Taipei 10617, Taiwan; \\ ${ }^{3}$ Department of Energy Engineering, National United University, Miaoli 36003, Taiwan.
}

Received: January 14, 2015 / Accepted: February 27, 2015

\begin{abstract}
While the role of $\mathrm{Ti}$ and Mo elements on precipitation strengthening in ferrite grains formed during austenite/ferrite transformation is very clear, some uncertainty still presents concerning influence of microalloying elements on bainite transformation. Therefore, the present study focuses on the precipitation behavior occurred in a Ti-Mo bearing steel during bainitic phase transformation under different heat treatment conditions, and the correlation of the precipitation behavior with hardness distribution. Through the present work, it is expected to achieve a better understanding of low-temperature precipitation behavior to assist metallurgists to find out the reason for maintaining a high hardness by longtime isothermal holding, which can provide insight to design a better quality steel product. Vickers hardness was measured from the 1C-2Ti-2Mo, 1C-2Ti-2Mo and 0.5C-1Ti-2Mo steels treated by isothermal holding at $550{ }^{\circ} \mathrm{C}$ for 5 to $60 \mathrm{~min}$. The average Vickers hardness was in the range of 245 - 276, 290 - 335 and 220 - 245, respectively. Therefore, higher hardness can be obtained if the steel containing higher carbon and microalloying elements can form precipitations in the ferrite matrix. On the other hand, increasing Vickers hardness with isothermal holding times indicates a good thermal stability character of complex carbides. The excellent thermal stability can be attributed to the addition of Mo element, which can inhibit the growth of carbides during longtime isothermal holding. Furthermore, the addition of Mo in the steel can avoid annihilation of dislocations during longtime aging. By taking advantages of these two effects, high strength can be
\end{abstract}

*Corresponding authors: sfchen@ntut.edu.tw; chentexas@ gmail.com achieved for high-strength low-alloy steels containing Mo element. Transmission electron microscopy image showed nano-sized carbides nucleated at dislocations, instead of interfacial precipitations within ferrite grain matrix, because the interface precipitation morphology only occurred accompanying the austenite decomposition reaction. However, the bainitic phase transformation was of a displacive transformation character, thus the complex carbides could not form during the bainitic phase transformation due to a very fast transformation velocity.

Keywords: Bainite; Carbide; High-strength low-alloy steel; Phase transformation; Precipitation.

\section{Introduction}

There is currently a huge demand for the automobile industry to develop high-strength steel without sacrificing formability. A new generation of high-strength automobile wheel steel, called NanoHiten, characterized by ferrite microstructure and nanosized TiMoC precipitates was successfully developed in 2004 (Funakawa et al., 2004). This advanced steel features both ultra-high strength and excellent stretch flange formability due to its uniform microstructure. Beside to this steel, other advanced steels, such as TRIP, DP and TWIP steels, are also prominent research topics in the recent years (Cohen et al., 1986; Matlock et al., 2005; Brani et al., 2006).

The ultimate microstructure of TRIP steel usually consists of allotriomorphic ferrite as a major phase, mixed with a total $30 \sim 40 \%$ of bainite, martensite, and carbon enriched retained austenite. Much of effort in the past focused on the microstructure evolution in the bainitic transformation process during manu- 
facturing the TRIP steel. The role of allotriomorphic ferrite and bainitic ferrite are not emphasized, since it general thought that the source of strength and formability of TRIP steel mainly results from the bainite and retained austenite, respectively. As pointed out by Bhadeshia et al. (1992), the occurring of blocky retained austenite and cementite in the bainitic steel are two main reasons to induce embrittle phenomenon of steel. They also proposed several methods to solve the embrittle problem: (1) addition of the silicon in the steel, which can prevent the precipitation of cementite in the retained austenite and avoid crack initiating at these sites; $(2)$ reducing the bainitic transformation temperature which can increase XTO; (3) reducing the overall carbon concentration of the steel, and hence the retained austenite can reach to its limiting composition at a later stage of reaction; and (4) adjusting or addition of substitution elements to move the TO curve of the phase diagram to a higher carbon concentration. Although the above methods can solve the problem of blocky austenite in the steel, the influence of microalloy addition is seldom reported. As stated in the previous studies (Chen et al., 2009; Davenport et al., 1968; Jang et al., 2012; Chen et al., 2014), the interface precipitation and supersaturated precipitation phenomenon occurred in the allotriomorphic ferrite can harden the matrix effectively, which is also expected to avoid blocky austenite existing in the bainitic microstructure, because the carbon atom is expected to combine with microalloy elements to form carbides.

Interface precipitation has been firstly proposed in the microallyed steel since 1960s (Gray et al., 1968). This regular array of carbides within ferrite matrix accompanying austenite/ ferrite transformation is believed to enhance the ferrite matrix profoundly due to its tiny size and large amount of quantity. Since then, much effort has focused on developing such precipitation morphology for various alloy carbides or carbonitride systems, including $\mathrm{VC}, \mathrm{NbC}, \mathrm{Mo} 2 \mathrm{C}$, and $\mathrm{Cr} 23 \mathrm{Cb}$ (Ricks et al., 1983). Several models, such as ledge mechanism (Honeycombe et al., 1976), quasi-ledge mechanism (Ricks et al., 1983), superledge mechanism (Chen et al., 2014), and fibrous mechanism (Xie et al., 2014), had been proposed to explain the interface precipitation mechanism in detail.

Therefore, the objective of present study is to discover the influence of microalloy elements on the bainite phase transformation during isothermal holding experiment. The different atomic ratios of $\mathrm{Ti} / \mathrm{Mo}$ steels are investigated to reveal the different physical metallurgy phenomenon occurring in the high-strength low-alloy (HSLA) steel.

\section{Experimental Procedure}

The as-received material was an HSLA steel plate (with a thickness of about $45 \mathrm{~mm}$ ) produced through high temperature soaking, hot rolling, and accelerated cooling. The chemical compositions of the steels are listed in Table 1. In the present work, all the isothermal aging treatments were carried out on a Dilatromic III RDP deformation dilatometer produced by Theta Industries, Inc. Before the preparation of dilatometric specimens, small pieces of steel were homogenized at $1250{ }^{\circ} \mathrm{C}$ for 2 days while sealed in a quartz tube filled with argon and subsequently
Table 1. Chemical compositions of three bearing steels (wt.\%).

\begin{tabular}{lcccccccc}
\hline Steel & $\mathbf{C}$ & $\mathbf{S i}$ & $\mathbf{M n}$ & $\mathbf{P}$ & $\mathbf{S}$ & $\mathrm{Ti}$ & Mo & $\mathbf{F e}$ \\
\hline 1.0C-1Ti-1Mo & 0.10 & 0.1 & 1.50 & 0.01 & 43 & 0.1 & 0.2 & Bal. \\
1.0C-2Ti-2Mo & 0.10 & 0.1 & 1.50 & 0.01 & 43 & 0.32 & 0.2 & Bal. \\
0.5C-1Ti-2Mo & 0.05 & 0.1 & 1.50 & 0.01 & 43 & 0.1 & 0.2 & Bal. \\
\hline
\end{tabular}

quenched in water. After a decarburization layer had been removed, the specimens were then machined into cylinders with 3 $\mathrm{mm}$ in diameter and $6 \mathrm{~mm}$ in length. The dilatometer was interfaced with a computer workstation (PDP 11/55 central processor) in order to analyze the resulting data. The software package (provided by Theta Industries, Inc.) allowed flexible and complete controls in the execution of the isothermal aging experiments. The length, time, and temperature information were recorded in microsecond intervals, and the level of vacuum was maintained at 10-5 torr to protect the specimens from oxidation. Schematic diagrams for the isothermal heat treatment experiment performed in the dilatomter are presented in Figure 1. After austenitizing at $1200{ }^{\circ} \mathrm{C}$ for $3 \mathrm{~min}$, the specimens were directly cooled to isothermal aging temperature $\left(550^{\circ} \mathrm{C}\right)$ with a cooling rate of about $20^{\circ} \mathrm{C} / \mathrm{s}$, isothermally held at this temperature for $5,10,60 \mathrm{~min}$, respectively, and then quenched to room temperature.

The corresponding microstructures were examined by optical microscopy and transmission electron microscopy. Both specimens were slit from the dilatometric specimens. Hardness measurements of the specimens to be examined were taken using a Vickers hardness tester with a load of $100 \mathrm{~g}$. In order to realize the precipitation status in the bainite structure, for each steel and processing condition, measurements from 100 different positions were used to plot the final microhardness distribution. Furthermore, In order to avoid the influence of strain fields caused by each indentation test and interference with other phases, the position and the distance of each indentation mark were carefully controlled to ensure that the indentation marks were within a ferrite grain.

Thin foil specimens were prepared for TEM from $0.25 \mathrm{~mm}$ thick discs slit from the specimens used in the dilatometric experiments. The discs were thinned by abrasion on silicon carbide paper and then electropolished in a twin jet electropolisher using a solution of $5 \%$ perchloric, $25 \%$ glycerol, and $70 \%$ ethanol at $-20{ }^{\circ} \mathrm{C}$ and $35 \mathrm{~V}$ potential. They were examined using a

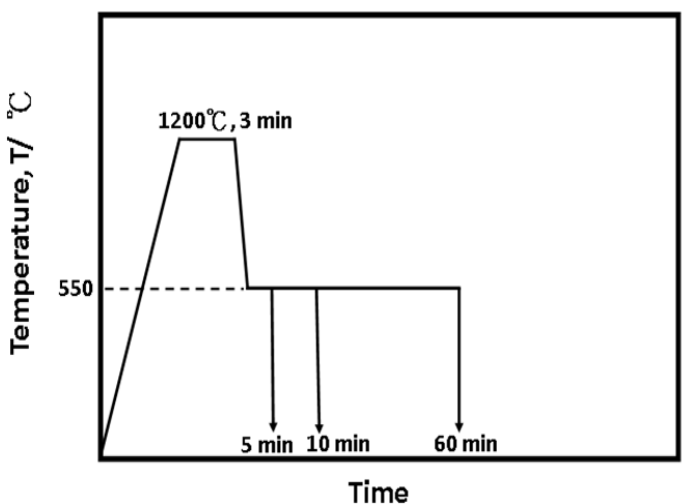

Figure 1. Schematic diagram illustrating heat treatment process. 
JEOL JEM 2000 EXII equipped with an energy dispersive X-ray spectrometer (EDS). The structural and compositional analyses of nano-sized carbides were examined using a FEG-TEM Tecnai F30 equipped with a nano-probe EDS.

\section{Results and Discussion}

Figure 2 shows the microstructure evolution of three steels with different atomic $\mathrm{Ti} / \mathrm{Mo}$ ratios under isothermal aging at $550{ }^{\circ} \mathrm{C}$. The phenomenon of interwoven or branching between bainite plate and retained austenite can be seen clearly in these figures. Prior austenite grain boundaries still exist because such displacive transformation cannot destroy the original microstructure, namely the length of bainitic ferrite would not penetrate from one austenite into another one. Since the bainitic phase transformation is expected to complete in a short period of time, thus the long-time holding makes a tempering effect of these steels which will be discussed later. A characteristic of the bainitic phase transformation is an invariant plane strain (IPS) which induces surface relief phenomenon. Another feature is also revealed in Fig. 2 that various length of bainitic ferrite plates appear in the steels with different carbon contents. The low carbon steel (i.e. 0.5C-1Ti-2Mo) has a wider thickness of bainite plate than high carbon steels (i.e. 1C-1 Ti-1 Mo and 1C-2Ti-2Mo)

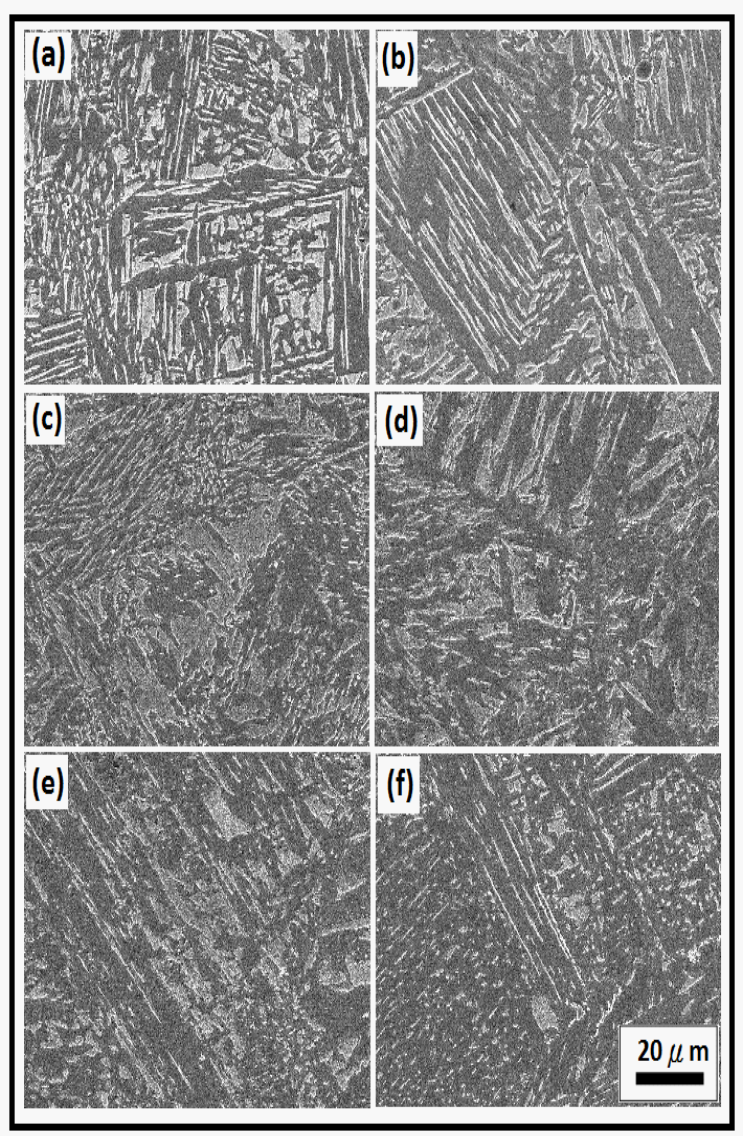

Figure 2. SEM for (a, b) 1C-1Ti-1Mo steel, (c, d) 1C-2Ti$2 \mathrm{Mo}$ steel and $(e, f) 0.5 \mathrm{C}-1 \mathrm{Ti}-2 \mathrm{Mo}$ steel isothermally aging treatment at $550^{\circ} \mathrm{C}$ for $(a, c, e) 10$ min and $(b, d, f) 60$ min. under the same isothermal aging condition. This phenomenon can be explained as follows: the thickness of bainite plate cannot increase isothermally since thickening of bainite plate should be plastically accommodated by neighboring austenite film (Chang et al., 1995; Singh et al., 1998). Therefore, dislocation forest generated from such an accommodation mechanism in the austenite inhibits the advances of the bainite/ austenite interface, introducing a higher resistance when the austenite is stronger. Therefore, stronger austenite is expected when the carbon content of the steel is high, which cannot accommodate the plastic deformation easily and get thinner bainite plates.

Figure 3 shows TEM image of upper bainite structure and corresponding diffraction pattern. From the electron diffraction pattern in Fig. 3(c), an N-W orientation relationship (OR) is found between the bainite ferrite and austenite film. This is reasonable sine a better lattice matching between retained austenite (FCC structure) and bainite ferrite (BCC structure) can nucleate easily when the orientation relationship maintains at $\mathrm{K}-\mathrm{S}$ or N-W OR, in consistence with the phenomenological theory of martensite crystallography (Christian et al., 1990). It is generally known that the original of bainitic phase transformation is nucleation of sub-unit at dissociation of dislocation, subsequently partition of carbon atoms into the austenite matrix which induces another sub-unit to nucleate when the carbon content of austenite reaches XTO. Therefore the plates in the same bainitic sheaf usually have small misorientation or nearly the same orientation, which can be called sympathetic transformation phenomenon.

This specific transformation phenomenon is defined as a nucleation of a precipitate crystal at an interphase boundary of a crystal of the same phase when these crystals differ in composition from their matrix phase throughout the transformation process. The growth of precipitate crystal is accompanied by an invariant-plane strain shape deformation. Therefore, the subsequent autocatalytic nucleation of precipitate crystal could be triggered by the strain state in the vicinity of the prior precipitate crystal (Chen et al., 2007).

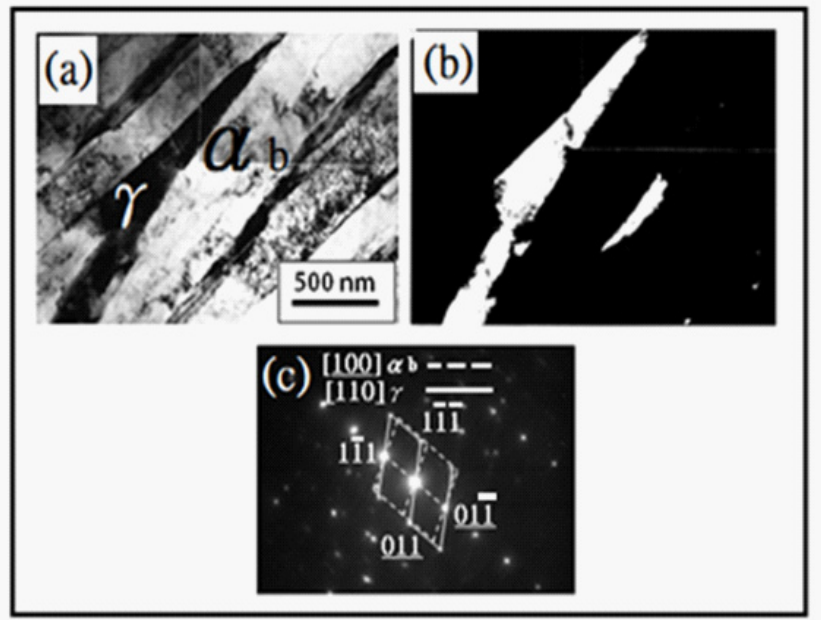

Figure 3. Bright-field (a) and dark-field (b) TEM images, and corresponding diffraction pattern (c) showing N-W orientation relationship exists between retained austenite and bainite ferrite in $1 \mathrm{C}-2 \mathrm{Ti}-2 \mathrm{Mo}$ steel aging at $550^{\circ} \mathrm{C}$ for $60 \mathrm{~min}$. 
Twinning martensite also appears in Figure 4, which should be resulted from the quenching process after isothermal aging, because the retained austenite can enrich carbon atoms after long time aging and generate twin martensite form retained austenite.

Another distinct feature occurred in the microalloyed steel during bainite transformation is the existence of microalloy carbides in the bainitic ferrite matrix, and these microalloy carbides should be formed in the austenite region due to their spherical shape as shown in Figure 5. Because many dislocations can be generated in the bainitic ferrite, these microalloy carbides are expected to grow fast by pipe diffusion of interstitial and substitutional atoms through dislocations. Therefore, more of bainite ferrite can be assumed to generate due to these existing microalloy carbides, benefiting for partition of carbon atoms to form bainite plates. The blocky austenite can be reduced further if the amount of microalloy carbides is sufficient to promote the bainitic transformation. These microalloy carbides can become large in size, especially when the carbide is located near the retained austenite, because it can serve as the sink for providing more interstitial and substitutional atoms through many dislocations.

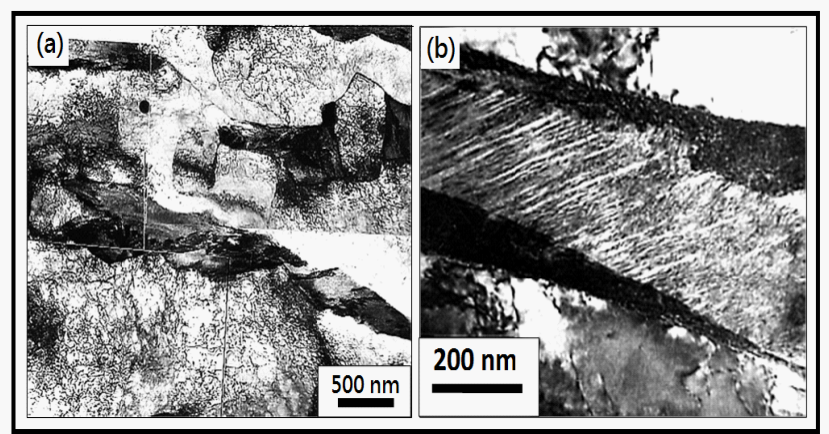

Figure 4. (a) low magnification and (b) high magnification brightfield images showing a lot of dislocation debris around retained austenite and twin martensite resulted from carbon enriched retained austenite during quenching process for $1 \mathrm{C}-2 \mathrm{Ti}-2 \mathrm{Mo}$ steel aging at $550^{\circ} \mathrm{C}$ for $60 \mathrm{~min}$.

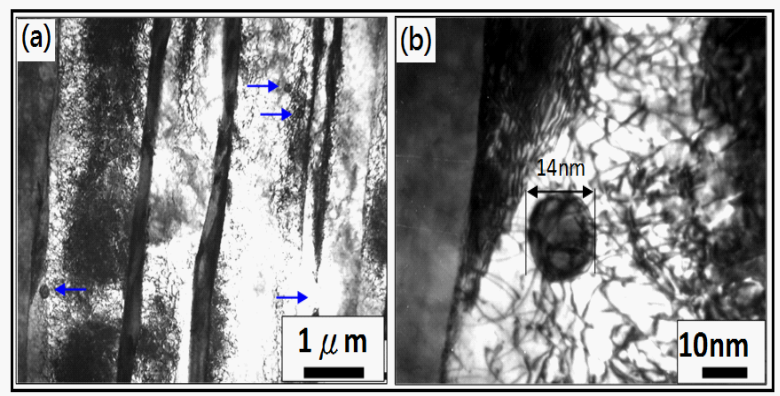

Figure 5. (a) low magnification and (b) high magnification bright field image, for $1 \mathrm{C}-1 \mathrm{Ti}-2 \mathrm{Mo}$ steel aging at $550^{\circ} \mathrm{C}$ for $60 \mathrm{~min}$, revealing spherical precipitation carbides, as indicated by arrows, forming at high temperature austenite region and would absorb carbon and other substitution atoms from nearby retained austenite and surrounding bainite plate through dislocation.
Figure 6 reveals pearlite structure after longtime aging. The root cause of appearing pearlite is mainly due to the carbon concentration in untransformed austenite region larger than that given by the extrapolated $\gamma /(\gamma+$ carbide) phase boundary (Kriesement et al., 1969). This is because the carbon concentration of austenite is expected to increase with isothermal aging times due to the partition of carbon atoms accompanying the bainite transformation. Therefore, the larger regions of austenite can form colonies of pearlite with a fine interlamellar spacing, whereas the films of austenite decompose into discrete particles of cementite in a matrix of ferrite.

The effect of addition different amount of microalloy elements on the bainite phase transformation can be analyzed form the microhardness data. Figure 7 reveals the variation of hardness with isothermal aging times at constant isothermal aging temperature $\left(550^{\circ} \mathrm{C}\right)$. Two obvious features can be outlined as follows: (1) although it shows different incremental in microhardness, the hardness values of all steels increase with isothermal aging times. (2) The higher $\mathrm{Ti} / \mathrm{Mo}$ atomic ratio can get larger microhardness during isothermal aging process. This is the second characteristic of addition microalloy elements in the steel for bainite transformation. The reason for elevating microhardness with aging times should be ascribed to the precipitation of carbides in the matrix. Indeed, Figure 8 shows the precipitation of

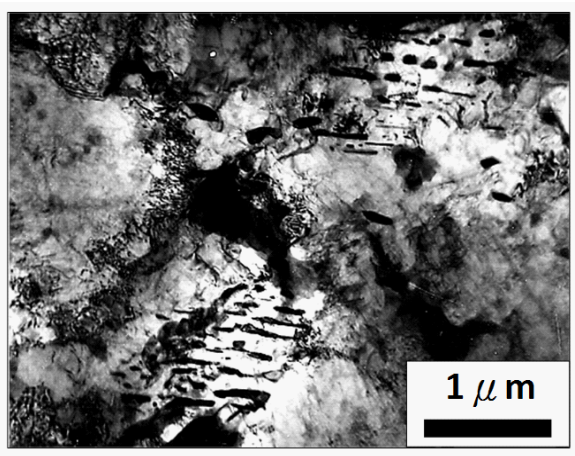

Figure 6. TEM bright field image showing tempering effect for 1C2Ti-2Mo steel. Pearlite and discrete carbide are observed, which are resulted from decomposition of blocky retained austenite and film retained austenite, respectively.

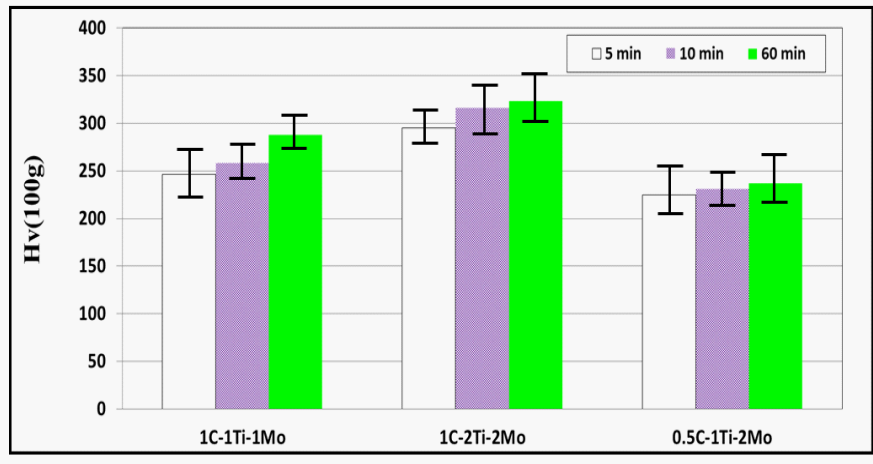

Figure 7. Vickers hardness of $1 \mathrm{C}-1 \mathrm{Ti}-1 \mathrm{Mo}, 1 \mathrm{C}-2 \mathrm{Ti}-2 \mathrm{Mo}$, and $0.5 \mathrm{C}$ $1 \mathrm{Ti}-2 \mathrm{Mo}$ bearing steels. $1 \mathrm{C}-2 \mathrm{Ti}-2 \mathrm{Mo}$ is the hardest steel than the other two, and the hardness increases with the isothermal holding time. 


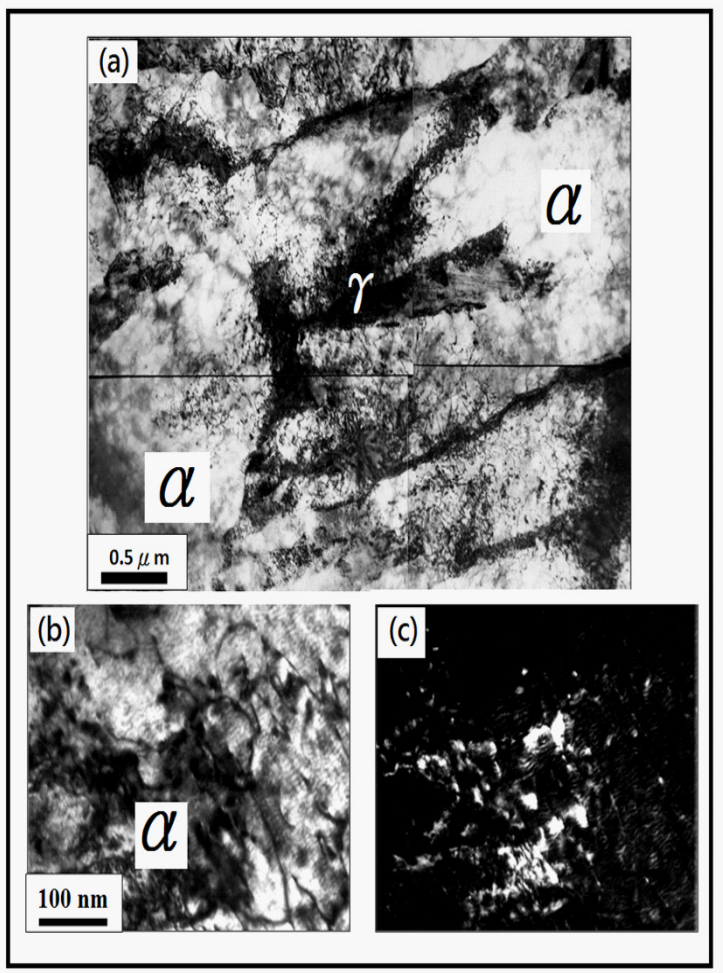

Figure 8. Low-magnification image (a), and high-magnification bright-field image (b) and corresponding darkfield image (c) showing nano-sized precipitation of carbides on the dislocations in the bainite ferrite matrix in $1 \mathrm{C}-2 \mathrm{Ti}-2 \mathrm{Mo}$ steel aged at $550^{\circ} \mathrm{C}$ for $5 \mathrm{~min}$.

nano-sized carbides at dislocation. The root cause of precipitation these nano-sized carbides is associated with a paraequilibrium phenomenon of displacive transformation (Bhadeshia et al., 1992), which leads to a situation that the microalloy elements cannot partition during the transformation process and remain in the bainite ferrite plates and retained austenite. Because the lower solubility of these microalloy elements prevails in the ferrite, the supersaturated precipitation of carbides occurs during the whole isothermal aging process (Gladman et al., 1999; Honeycombe et al., 1976).

It is also indicated in the Figure 8 that these nano-sized carbides obey the Baker-Nutting orientation relationship with three different variants, which indicates that these carbides are nucleation directly from bainite ferrite matrix (Smith et al., 1988). These carbides would nucleate at dislocations resulting bainitic phase transformation, and grow slowly due to low diffusivity of microalloy elements when the isothermal aging is conducted at a low temperature. Therefore the hardness result of these steels is consistent with the fact that a higher $\mathrm{Ti} / \mathrm{Mo}$ atomic ratio leads to larger volume fraction of precipitation carbides. From the above discussion, the relationship between microalloy elements and bainite phase transformation can be drawn as follows: (1) microalloy carbides formed in the austenite region have spherical shape, which can absorb carbon atoms, promote bainite phase transformation, and inhibit blocky retained austenite in the steel;
(2) microalloy elements at a high temperature exist in the whole microstructure including bainite ferrite plates and retained austenite during the bainitic phase transformation. These microalloy elements would nucleate at dislocation and form supersaturated precipitation carbides in the bainitic ferrite, which can increase the hardness effectively. For the TRIP steel, addition of microalloy elements should enhance the mechanical properties by precipitating of nano-sized carbide in the allotriomorphic ferrite as well as bainitic ferrite and avoiding appearance of blocky retained austenite in the steel. Although the positive effect of addition microalloy elements in the steel emphasize in the present text, some problems like the role of $\mathrm{Si}$ and precipitation of these nano-sized carbides in the low bainite needs further study.

\section{Conclusion}

From the experimental results and discussion, some conclusions are obtained as follows:

(1) Microalloy carbides formed in the high-temperature austenite region can absorb interstitial and substitutional atoms by pipe diffusion, which would promote the bainite transformation and reduce the occurrence of blocky retained austenite in the steel.

(2) The sub-units of identical bainite sheaf have almost the same orientation, which is a characteristic of sympathetic transformation.

(3) Bainite plates are large in the low-carbon steel, due to a large plastic accommodation ability provided by the soft austenite matrix.

\section{References}

Bhadeshia HKDH (1992) Bainite in Steels. The Institute of Materials, London.

Brani AB, D Ponge, and D Raabe (2006) Strong and ductile martensitic steels for automotive applications. Steel Research Int. 77:704-711.

Chen CY, HW Yen, and JR Yang (2007) Sympathetic nucleation of austenite in a $\mathrm{Fe}-22 \mathrm{Cr}-5 \mathrm{Ni}$ duplex stainless steel. Scripta Mater. 56: 673-676.

Chen CY, HW Yen, FH Kao, WC Li, CY Huang, JR Yang and SH Wang (2009) Precipitation hardening of high-strength low-alloy steels by nanometer-sized carbides. Mater. Sci. Eng. A 499: 162-166.

Chen J, MY Lv, S Tang, ZY Liu, and GD Wang (2014) Influence of cooling paths on microstructural characteristics and precipitation behaviors in a low carbon V-Ti microalloyed steel. Mater. Sci. Eng. A 594: 389-393.

Chen MY, M Gouné, MVerdier, Y Bréchet, and JR. Yang (2014) Interphase Precipitation in Vanadium-alloyed Steels: Strengthening Contribution and Morphological Variability with Austenite to Ferrite Transformation, Acta Mater. 64:78-92.

Christian JW (1990) Simple geometry and crystallography applied to ferrous bainites. Metal. Trans. A 21 A:799-803.

Cohen M and SS Hansen (2005) HSLA steels, metallurgy and applications: proceedings of an International Conference on HSLA Steels. 85: $61-71$.

Davenport AT, FG Berry, and RWK Honeycombe (1968) Interface Precipitation in iron alloys. Met. Sci. 2: 104-104. 
Funakawa Y, T Shiozaki, K Tomita, T Yamamoto, and E Maeda (2004) Development of High Strength Hot-rolled Sheet Steel Consisting of Ferrite and Nanometer-sized Carbides. ISIJ inter. 44: 1945-1951.

Gladman T (1999) Precipitation hardening in metals. Materials Science and Technology 15:30-36.

Gray JM and RBG Yeo (1968) Niobium carbonitride precipitation in low-alloy stels with particular emphasis on precipitate-row formation. Trans. ASM 61:255-269.

Honeycombe RWK (1976) Transformation from Austenite in Alloy Steels. Metall. Trans A. 7A:915-936.

Jang JH, CH Lee, YU Heo, and DW Suh (2012) Stability of (Ti, M) C $(M=N b, V, M o$ and $W)$ carbide in steels using first-principles calculations. Acta Mater 60: 208-217.LC Chang, and HKDH Bhadeshia (1995) Austenite films in bainitic microstructures. Mater. Sci. and Technol. 11:874-881.

Kriesement $O$ and F Wever (1969) Mechanism of Phase Transforma- tions in Metals, Institute of Metals, Monograph and Rep. Ser. No. 1. Matlock DK, G Krauss, and JG Speer (2005) New Microalloyed Steel Applications for the Automotive Sector. Mater. Sci. Forum. 500501:87-96.

Ricks RA and PR Howell (1983) The formation of discrete precipitate dispersions on mobile interphase boundaries in iron-base alloys. Acta Metall. 31:853-861.

Singh SB and HKDH Badeshia (1998) Estimation of bainite plate-thickness in low-alloy steels. Mater. Sci. Eng. A 245:72-79.

Smith RM and DP Dunne (1988) Structural aspects of alloy carbonitride precipitation in microalloyed steels. Mater. Forum. 11:166-181.

Xie H, LX Du, J Hu, and RDK. Misra (2014) Microstructure and mechanical properties of a novel $1000 \mathrm{MPa}$ grade TMCP low carbon microalloyed steel with combination of high strength and excellent toughness, Mater. Sci. Eng. A. 612:123-130. 